\title{
La biblioteca: un escenario diverso para la promoción de la lectura
}

\author{
Lorena Chaves Salgado
}

Sección Especial 6| Recibido: 23 de noviembre del 2018| Aceptado: 30 de noviembre del 2018 | Publicado: 01 de enero de 2019

\section{DOI: https://doi.org/10.15517/eci.v1i1.35436}

e-Ciencias de la Información, volumen 9, número 1, Ene-Jun 2019

ISSN: $1649-4142$

\section{다(1)(5)(2)}

\section{¿Cómo citar este artículo?}




\title{
La biblioteca: un escenario diverso para la promoción de la lectura
}

\author{
Lorena Chaves Salgado $^{1}$
}

\author{
Son palabras \\ Vuelan alto \\ mágicas, de colores; \\ así son las palabras. \\ Cantan, susurran \\ se mueven \\ así son las palabras. \\ Alegres, sonoras \\ azules como el cielo; \\ así son las palabras.
}

Del libro: Amanecer de Colores

Palabras Clave: goce por la lectura; biblioteca escolar; biblioteca pública;

fomento a la lectura.

La biblioteca pública y la biblioteca escolar se proyectan y se comprenden desde los espacios mediados por actividades y experiencias vinculadas al concepto de "promoción de la lectura". Ambas bibliotecas constituyen un medio fundamental de formación integral para la vida a través de la lectura como práctica social y cultural; por su naturaleza de instituciones democráticas abiertas a toda la sociedad, han de responder a las necesidades de personas y grupos.

En la actualidad, la biblioteca no puede restringirse a cumplir con sus labores tradicionales, por el contrario, es inminente dar respuesta a las demandas que podríamos denominar de crecimiento personal, entendiéndolas como la capacidad que tenemos todas las personas para aprender, experimentar desafíos, experiencias nuevas y desarrollarnos de forma activa y libre, poniendo en práctica, en todo momento, oportunidades de mejoramiento personal que coadayuven a plantearnos nuestra vida de manera integral, proyectando logros que nos fortalezcan ante distintas situaciones que debemos enfrentar.

Las bibliotecas pública y escolar constituyen un centro de información y de 
recursos con un papel relevante, donde la formación del hábito lector en las personas debe ser una labor constante y encomiable, que conlleva diseñar y poner en práctica programas que respondan a las necesidades de las distintas poblaciones que las visitan. Debemos preguntarnos, entonces, ¿qué significado adquiere en la vida del ser humano el acto de leer? La respuesta es que la lectura, como agente de cambio, debe comenzar desde que damos nuestros primeros pasos y tiene que transcurrir a lo largo de toda nuestra vida. La lectura nos enseña el camino hacia el conocimiento, nos hace adentrarnos en una experiencia de aprendizaje continuo, de renovación y, sobre todo, de sorpresa y de emoción.

Sentimientos que se experimentan al abrir un libro y tocar sus páginas, al mirar sus ilustraciones y al descifrar un mundo mediado por la palabra, por ese encuentro espontáneo que significa la lectura donde se tienen que multiplicar los afectos y las emociones hacia esta práctica. Entonces, ese lector, el gran protagonista, no debe concebirse como un ser pasivo, al contrario, tiene que entablar una relación activa con el texto escrito, una comunicación personal, un diálogo interno de reflexión, porque cada persona lee desde sí misma, desde su conocimiento sobre un tema, desde su interioridad, dándole una interpretación a sus lecturas desde su propia visión de mundo, porque la lectura no es una sencilla acción de descodificar códigos, nada de eso, conlleva un proceso o trabajo en el cual la persona tiene que estructurar una compleja construcción de significados, para poder leer y comprender un texto. Aquellos que decidan acercarse y participar del acto lector van a vivirlo como una práctica activa que les permita descubrirse en un mundo diverso de muchos matices y en un acto individual. La experiencia lectora se convierte en una vivencia muy gratificante que despierta en el lector el deseo y el entusiasmo, de entender el mundo que está hecho de palabras.

Esta práctica social y cultural se adentra en la construcción y el aprendizaje de nuevos conocimientos que dan sentido a la vida de las personas, por medio de una visión de la realidad, enmarcada en una transformación constante de un lector que debe mantener una relación dialógica e incesante con el texto, porque, en esencia, leer es un acontecimiento de comprensión, de discernimiento que para el lector va a ocurrir en un momento y dentro de un contexto particular de experiencias personales; en ese sentido, nuestra historia como lectores se edifica con el ejercicio y el disfrute de la lectura, en ese caminar que es adentrarse en un universo que trasciende lo personal que nos permite generar una reflexión que tiene que ver con ese enigmático acto que resulta ser la lectura.

Los caminos del lector están mediados por la conciencia de nuestro ser, en un reconocimiento de nuestras visiones de mundo, en un constante descubrimiento de la palabra escondida que es aquella que no hemos leído aún, que no hemos descubierto con curiosidad. Son, entonces, los libros los que deben acompañarnos a través de nuestra vida de la forma más fiel, porque leer es toda una aventura maravillosa mediada por un sinfín de mundos posibles. 


\section{ênformación}
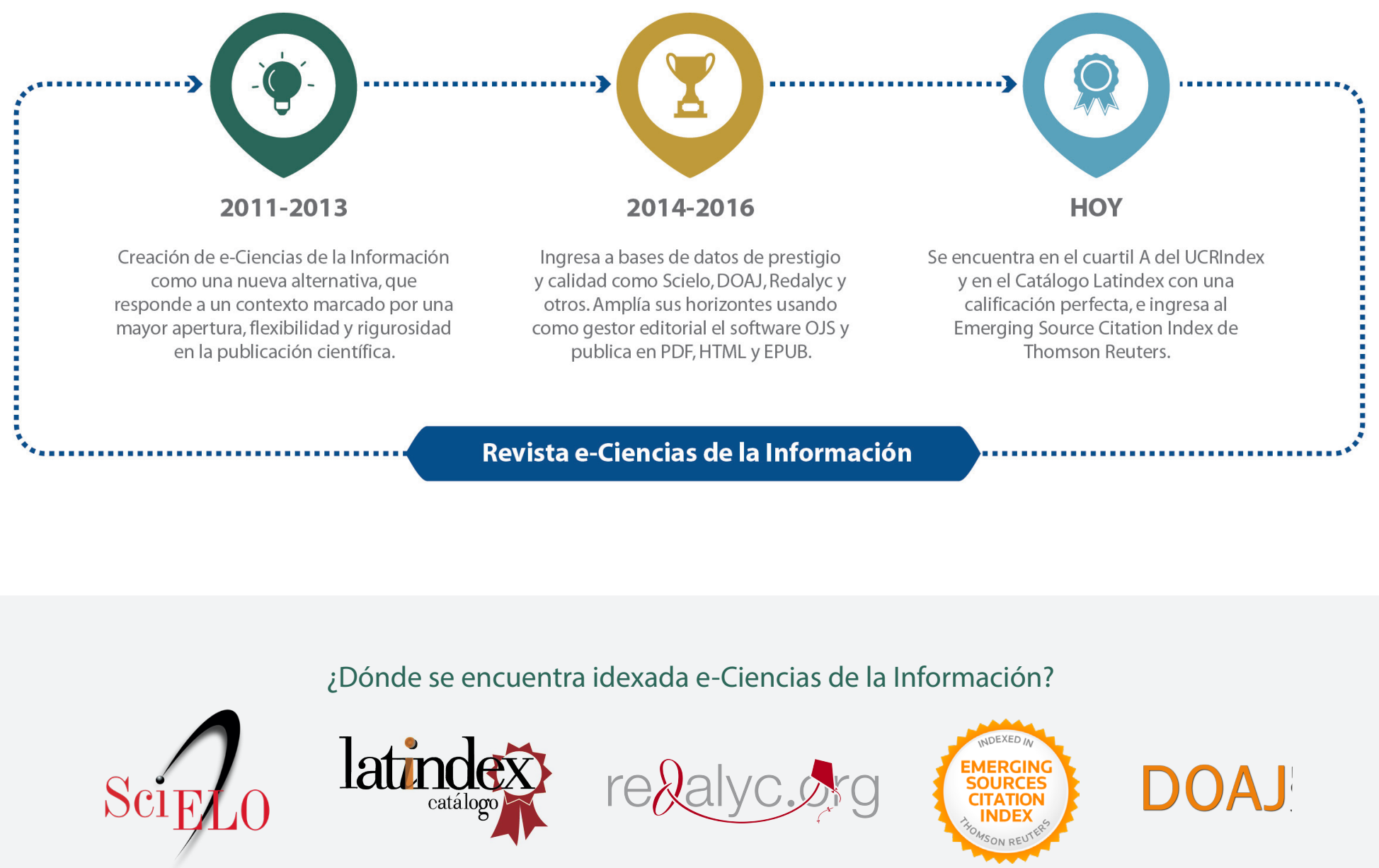

¿Dónde se encuentra idexada e-Ciencias de la Información?
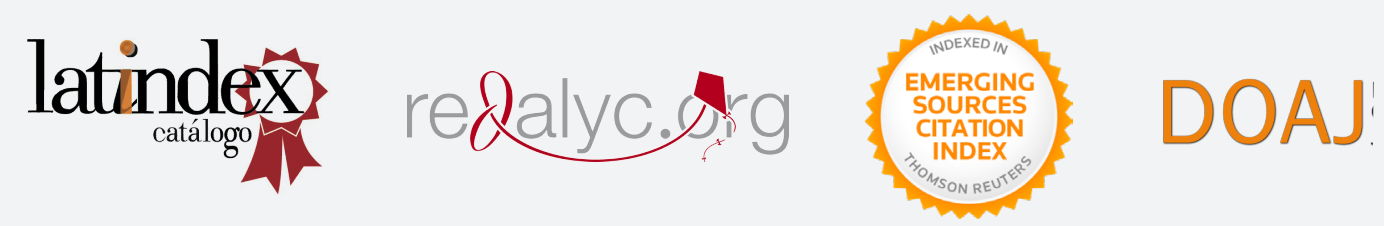

Para más información ingrese a nuestra lista completa de indexadores

¿Desea publicar su trabajo?

Ingrese aquí

O escríbanos a la siguiente dirección revista.ebci@ucr.ac.cr 